\title{
The Distance to a Star: Subject Measurement of the Library of Congress and University of Florida Collections
}

\begin{abstract}
A study was undertaken at the University of Florida libraries to compare holdings with those of the Library of Congress. It was concerned with relative proportions in various subject categories corresponding to areas of purchasing at Florida. Its object was the provision of data so that the book-fund allocation formula might be weighted to favor funds from which substantial retrospective purchasing was desirable. Sampling and shelflist measurement provided the major sources. As a byproduct, the study provided a basis for comparing holdings of the two libraries which revealed an extremely high correlation in subject content, distributed in twenty-eight subject fields.
\end{abstract}

$\mathrm{I}_{\mathrm{r}}$ university library would seek to compare its holdings with those of the Library of Congress in terms of the distribution of subject matter in the collections of the two institutions. The university library could assume, with good reason, that its

Mr. Kebabian is Director of the Library, University of Vermont, and former Associate Director in the University of Florida Library. Sources in the University of Florida Libraries include "Report to Library Committee from Library Staff Committee on Book and Periodical Allocations, May 16, 1949"; memorandum, "Revision of Factor D: Depth of Field," May (P) 1954; letter to Mr. West from Miss Prince, May 14, 1954; tabulation of sampling done in March 1965; "Minutes" of the Sub-committee on Allocations of Library Book Funds, January 7-June 2, 1965; and "Report" of the Subcommittee on Allocations of Library Book Funds, April 23, 1965. All are unpublished and not available for distribution. collections had been developed to fulfill requirements for books appropriate to the courses offered and to the research needs of its academic community over a period of years; that emphases in the curricula would have varied over the years and the scope of the collections would accordingly reflect these emphases by either selectivity or comprehensiveness in certain subjects; that because of quite differing aims there would be no reasons for assuming that the collections of the university library and those of the Library of Congress would be subject comparable; and that as a consequence of these assumptions one might postulate that there could be little gain in making such comparisons.

Relative proportions of the Library of Congress and the University of Florida libraries holdings have nonetheless been measured by the latter institution on at least three occasions, of which the earliest was in 1949, for the purpose of de- 
veloping a "depth-of-field" factor. This factor is one of several in a formula used in budgeting that portion of the library funds distributed to colleges and departments of the university for the purchase of books and periodicals, and for binding. What follows is in no sense concerned with the pros and cons of "allocation" as a method of distributing book funds; its object is rather to report some part of the findings of a specific investigation.

Depth of field, as a formula factor, was conceived as a method of taking into account, in the distribution of funds, the whole of publishing history and where the Florida library stood in its collecting in relation to numbers of books printed since 1450 in a broad range of subject areas. Stating the need in another way, the University of Florida libraries constitute a relatively young collection, with holdings of about 525,000 volumes as recently as 1953. It was argued that in terms of all published books and the need for acquisitions in those disciplines with a longer printing history, more funds should be expended to achieve the retrospective collections needed, for example, in history, language, and literature than to provide for retrospective purchases in newer subject areas with a significantly shorter and less voluminous printing history, such as the sciences.

Given the object, then, of measuring publishing over a most broad spectrum of subjects, it was decided that the printed catalogs of the Library of Congress represented the one best and readily available source for such measurement. In preparation of the 1949/50 allocation formula, two thousand titles were sampled in A Catalog of Books Represented by Library of Congress Printed Cards (cards issued from August 1898 through July 1942). The technique in sampling and recording of information about the titles searched was substantially the same as that followed some five years later when a more extensive study was made.

In the spring of 1954, under the direction of Vivian Prince, then head of the technical processes department, a sampling was again made of A Catalog of Books Represented by Library of Congress Printed Cards, and the first Supplement (cards issued from August 1942 through December 1947). In this sampling, over seven thousand titles were checked in the 209 volumes and distributed among some one hundred and seventy discrete categories according to Dewey Decimal Classification. The titles were then searched in the union card catalog of the university libraries, and for each title a record made of whether or not it was represented.

In reporting the findings to Stanley L. West, director of libraries, Miss Prince took note of the fact that the printed catalogs which had been systematically sampled did not in fact represent the collections of the Library of Congress, but only that part of the collections for which catalog cards had been printed; that the Bible, government documents, English and American fiction, and American trade books acquired by copyright deposit were some of the areas in which the LC catalog was heavily weighted while other fields, for example foreign languages and literatures, were not well represented; and that there was no necessary relationship between the subject balance of the Library of Congress collections and those of a modern university library. But because the LC catalogs did offer an approach to the totality of printed books, the findings of this sampling were utilized in the preparation of a depth-of-field factor in the book allocations prepared for the fiscal biennium 1955-57 and were taken into account in the distribution of funds in the next four biennia.

Early in 1965 a subcommittee of the Committee on University Libraries was charged with the preparation of a new 
schedule for the allocation of college and departmental library funds. (The funds so allocated ultimately represented in the 1965-66 budget 55 per cent of the total, while funds for "library general" were 45 per cent.) Again, the subcommittee agreed that depth of field should be incorporated as an element of the allocation formula. It was decided that the 1954 sampling should be brought up to date by adding an additional sampling which would enlarge the universe and perhaps confirm the earlier findings. The new sampling base used was The $\mathrm{Li}$ brary of Congress Author Catalog, 19481952, and The National Union Catalog, a Cumulative Author List, 1953-1957.

With the advice of Willard $\mathrm{O}$. Ash, professor of statistics, a new and substantially different application of the sampling was developed. Rather than working up data based on what specific titles the libraries had acquired of those LC titles sampled, as had been done in the 1954 analysis, a measurement of the distance between the University of Florida holdings and the Library of Congress holdings was sought.

From the 1954 sample, the 7,027 titles were assigned to twenty-eight categories corresponding to departmental and college acquisition funds. The sample was reduced to 6,195 in this process because not all titles could be so assigned. From the 1965 sampling of The Library of Congress Author Catalog and The Na-

TABLE 1.

Percentages of Library of Congress Holdings and University of Florida Holdings in Designated Subject Areas

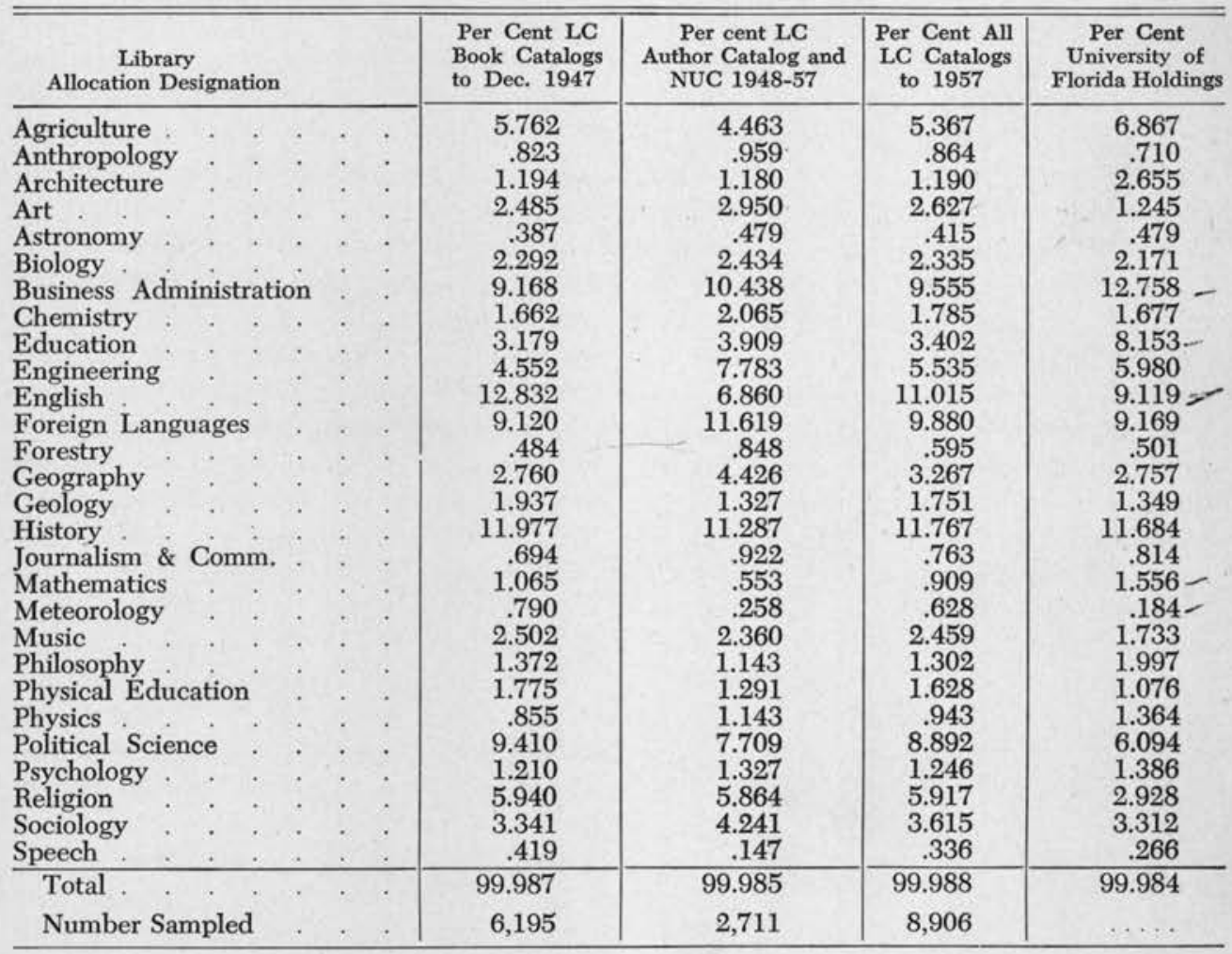


tional Union Catalog covering the period 1948 through $1957,2,711$ of 2,898 items were similarly assigned to the departmental designations, providing a total sample of 8,906 .

It is not relevant to this report to explain the development and the application of the measurement of distance, and the ultimate resultant depth-of-field factor, since as used in the formula the interdisciplinary purchasing patterns of departments and colleges were also taken into account. What is significant, however, is the comparison of the University of Florida holdings, derived from a shelflist measurement, distributed among the twenty-eight departmental and college funds, and the sampling of the Library of Congress book catalog entries distributed in a like manner.

Referring to Table 1, the similarity of the percentages in the Library of Congress collections up to 1947 with those of the period 1948-1957 (columns 2 and 3 ) is striking, and the sample studies tend to reinforce and validate each other. Where there are differences of some degree, they are in most instances predictable: sciences such as biology, chemistry, engineering, and physics show gains in the 1948-1957 period, while the relative proportions of titles in English, history, and political science have decreased.

What is more unexpected is the surprisingly high correlation, shown in columns 4 and 5 of the table, between the individual Library of Congress percentages and the corresponding percentages of holdings of the University of Florida libraries. The instances wherein the Florida holdings show any appreciable variation on the plus side are, in three of four cases, those book fund areas represented on the campus by well established colleges of agriculture, business administration, and education. Two of these colleges have separate libraries. But in twenty instances the differences in the proportions of LC and Florida holdings are fractional. In no case is the variation in the percentages greater than 5 per cent.

A comparative study of the subject relationship of the collections of the two institutions as of 1954 and 1965 has not been made since the necessary data were not available. But, that depth of field did become a factor in the book fund allocation process at Florida during the intervening years may partially explain why the proportions of the collections have become as close as they are.

On the evidence of the figures in columns 4 and 5 , it appears that these two libraries, one of about one million one hundred thousand volumes and the other of several millions, differing in over-all patterns of devélopment, in clientele served, in the span of time during which the collections were gathered, and in the comprehensiveness or completeness of their collections have nevertheless acquired total holdings which are significantly equal in the proportions each of the subject areas reported bears to the whole of their individual collections.

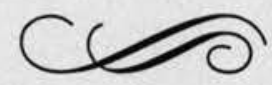

